\title{
Inhibition of Protein Aggregation by Several Antioxidants
}

\author{
Samra Hasanbašić, ${ }^{1,2}$ Alma Jahić, ${ }^{1}$ Selma Berbić, ${ }^{1}$ Magda Tušek Žnidarič $\mathbb{D},{ }^{3}$ \\ and Eva Žerovnik (iD $2,4,5$ \\ ${ }^{1}$ Faculty of Pharmacy, Department of Biochemistry, University of Tuzla, Univerzitetska 1, 75000 Tuzla, Bosnia and Herzegovina \\ ${ }^{2}$ Jožef Stefan International Postgraduate School, Jamova 39, SI-1000 Ljubljana, Slovenia \\ ${ }^{3}$ Department of Biotechnology and Systems Biology, National Institute of Biology, Večna pot 111, SI-1000 Ljubljana, Slovenia \\ ${ }^{4}$ Department of Biochemistry and Molecular and Structural Biology, Jožef Stefan Institute, Jamova 39, SI-1000 Ljubljana, Slovenia \\ ${ }^{5}$ Center of Excellence for Integrated Approaches in Chemistry and Biology of Proteins (CipKeBip), Jamova 39, \\ SI-1000 Ljubljana, Slovenia
}

Correspondence should be addressed to Eva Žerovnik; eva.zerovnik@ijs.si

Received 17 September 2017; Revised 31 December 2017; Accepted 9 January 2018; Published 25 March 2018

Academic Editor: Swaran J. S. Flora

Copyright (C) 2018 Samra Hasanbašić et al. This is an open access article distributed under the Creative Commons Attribution License, which permits unrestricted use, distribution, and reproduction in any medium, provided the original work is properly cited.

\begin{abstract}
Amyloid fibril formation is a shared property of all proteins; therefore, model proteins can be used to study this process. We measured protein aggregation of the model amyloid-forming protein stefin $\mathrm{B}$ in the presence and absence of several antioxidants. Amyloid fibril formation by stefin B was routinely induced at $\mathrm{pH} 5$ and $10 \% \mathrm{TFE}$, at room temperature. The effects of antioxidants NAC, vitamin C, vitamin E, and the three polyphenols resveratrol, quercetin, and curcumin on the kinetics of fibril formation were followed using ThT fluorescence. Concomitantly, the morphology and amount of the aggregates and fibrils were checked by transmission electron microscopy (TEM). The concentration of the antioxidants was varied, and it was observed that different modes of action apply at low or high concentrations relative to the binding constant. In order to obtain more insight into the possible mode of binding, docking of NAC, vitamin $\mathrm{C}$, and all three polyphenols was done to the monomeric form of stefin $B$.
\end{abstract}

\section{Introduction}

Properties of the amyloid state are generic to all proteins $[1-3]$, whereas subtle differences in sequence and $3 \mathrm{D}$ structure dictate the propensity to form such ordered aggregates $[4,5]$. Even though practically any protein can be induced to form the amyloid state in vitro, only about 50 of amyloidogenic proteins aggregate in vivo and cause disease $[6,7]$. The aggregation of proteins finally leads to amyloid fibrils, which get sequestered into different inclusion bodies, whereas most dangerous proved soluble oligomers, which likely bind and perforate membranes causing toxicity. Therapy for neurodegenerative diseases, which would attack the roots of this pathological process and even cure the disease, is urgently needed, due to the aging population. Ways of how to stop the aberrant process of protein aggregation at a particular point are several [8]. One way is to support the native state by stabilizing antibodies, yet another is to recruit chaperone proteins or augment degradation pathways [9-14]. However, these new ways of possible early treatments are still under investigation in animal models and clinical trials.

Oxidative stress (OS) is one of the most important characteristics of neurodegenerative diseases [15]. It is known that it modifies proteins and causes their misfolding and aggregation. On the other side, protein aggregates bind divalent metal ions $\left(\mathrm{Fe}^{2+}\right.$ and $\left.\mathrm{Cu}^{2+}\right)$, which in combination with hydrogen peroxide leads to the formation of reactive oxygen species (ROS) [16]. Therefore, neuroprotection by reducing protein aggregates or ROS or both seem achievable pharmacological targets [17]. However, very few effective compounds have been developed for clinical application and even fewer have been successful because of their toxicity and potential carcinogenicity. Natural antioxidants provide neuroprotective effects through a variety of biological 
actions, such as scavenging free radicals, interaction with transition metals, modulation of different enzymes and effects on intracellular signaling pathways, and gene expression [17]. Several epidemiological studies suggest that diets rich in antioxidants offer protection against numerous pathologies such as cancer, heart disease, hypertension, neurodegenerative diseases, and stroke $[17,18]$. One should keep in mind that therapeutic use of relatively safe natural polyphenols is limited by their pharmacokinetics. In addition, these compounds can hardly pass the blood-brain barrier and reach an active concentration in the brain [17]. Some derivatives may act better; for example, it was shown that metal complexes of curcumin inhibited more potently the fibrillation of amyloid-beta $(\mathrm{A} \beta)$ than the parent compound did [19].

Knowing that protein aggregation is a shared property of all proteins, model proteins can be used to study this process. We have studied many facets of oligomers and amyloid-like fibril formation by human stefin B [20-25]. Here, we use this system to study the effect of various antioxidant substances on the kinetics, yield, and morphology of amyloid fibril formation. For this study, we have chosen vitamins $\mathrm{C}$ (vit $\mathrm{C}$ ) and $\mathrm{E}$ (vit E), $\mathrm{N}$-acetyl cysteine (NAC), and three polyphenols: curcumin (Cur), resveratrol (Res), and quercetin (Quer) (Figure 1). Vitamins C and E and NAC, as well as polyphenolic compounds, reduce reactive oxygen species by their free electron scavenging action [26]. However, they also may directly interact with a protein hydrogen-bonding network or aromatic residues, respectively, with an impact on protein aggregation $[27,28]$.

NAC ((2R)-2-acetamido-3-sulfanyl propanoic acid) (Figure 1(a)) has been shown to be an effective precursor to glutathione $(\mathrm{GSH})$ production, and it is known to cross the blood-brain barrier (BBB) [29]. It provides cysteine, which is the rate-limiting substrate in glutathione synthesis. Therefore, it acts as an antioxidant by increasing GSH levels and by directly interacting with free radicals [29]. Its ability to effectively disrupt the fibrillogenesis of the $\mathrm{A} \beta$ peptide has already been reported [30]. Vitamin C ((2R)-2-[(1S)-1,2dihydroxyethyl]-3,4-dihydroxy-2H-furan-5-one) is believed to be a vital antioxidant in the brain (Figure 1(b)) [31]. Namely, a huge body of evidence suggests that vitamin $\mathrm{C}$ may change the course of neurological diseases and serve as a potential therapeutic tool. Intracellularly, it helps to maintain several key processes, including neuronal maturation and differentiation, myelin formation, synthesis of catecholamine, modulation of neurotransmission, and antioxidant protection [31]. Targeted deletion of the sodium-vitamin C cotransporter in mice resulted in widespread cerebral hemorrhage and death [31].

Polyphenols are secondary plant metabolites characterized by aromatic rings and one or more hydroxyl groups with different structural complexities (Figures 1(c)-1(e)). The most abundant class of phenolic compounds in plants includes flavonoids, such as flavonols, flavones, isoflavones, and anthocyanidins. Resveratrol (3,5,40-trihydroxystilbene) (Figure 1(c)) is an abundant polyphenol, a phytoalexin present in red wine and grapes. It has two phenolic rings connected by a double bond and has two isoforms trans- resveratrol and cis-resveratrol. trans-Resveratrol is believed to be responsible for the French paradox [32, 33]. A huge body of evidence shows its effects on the amyloid fibrillation process [34-37]. One of the most common dietary polyphenols is flavonol quercetin (2-(3,4-dihydroxyphenyl)-3,5,7-trihydroxy-4H-chromen-4-one) (Figure 1(d)). Quercetin is widely present in apples, tea, capers, and onions. Its inhibitory activity toward amyloid fibrillation has already been reported [38-41]. Curcumin ((1E,6E)-1,7-bis(4-hydroxy-3methoxyphenyl)hepta-1,6-diene-3,5-dione) is a yellow pigment present in spice turmeric (lat. Curcuma longa) (Figure 1(e)). According to over 6000 citations, it has been associated with many beneficient activities, such as antiamyloidogenic, antioxidant, anti-inflammatory, anticancer, antiviral, and antibacterial $[42,43]$. On top of that, over one hundred clinical studies have been carried out with curcumin. Searching the literature, curcumin has been shown to inhibit amyloid fibrillation of $\mathrm{fA} \beta[44,45]$, prion protein [46], insulin [47], hen egg white [48], lysozyme [49, 50], and $\beta$-lactoglobulin [51]. Unfortunately, its wide application is limited due to its pharmacokinetics, which disfavors its bioavailability. Various formulations of curcumin that are currently available and ongoing studies should help to overcome this problem [42].

\section{Materials and Methods}

2.1. Materials. In this study, we have used human stefin $\mathrm{B}$ (stB wt) as a model protein. This recombinant protein has Cys 3 replaced with Ser. 2,2,2-Trifluoroethanol (TFE) was purchased from Fluka, Thioflavin T (ThT) from Aldrich, and bis(sulfosuccinimidyl)suberate $\left(\mathrm{BS}^{3}\right)$ from Thermo Fisher Scientific. Other chemicals were from Sigma, Carlo Erba, Serva, and Merck.

2.2. Expression and Purification. Expression and purification have already been described elsewhere [52]. Briefly, DNA constructs were transformed into the BL21(DE3)pLysS strain of E. coli. Expression was induced with IPTG (final concentration $1 \mathrm{mM}$ ). Three hours after induction, cells were separated from the medium and lysed. Expression efficiency was checked by SDS-PAGE electrophoresis. Cell lysates were additionally purified by adding $4 \%$ polyethyleneimine (PEI) and repeated centrifugation. This way, most of the contaminants such as nucleic acids and most bacterial (predominantly acidic) proteins were removed from the lysate. The stB wt was isolated from purified cell lysates by affinity chromatography on carboxymethyl (CM)papain-Sepharose. The nonspecifically bound material was eluted with $0.01 \mathrm{M}$ Tris- $\mathrm{HCl}$ containing $0.5 \mathrm{M} \mathrm{NaCl}$ at $\mathrm{pH}$ 8.0. The wt stefin B was eluted with $0.02 \mathrm{M}$ TEA buffer at $\mathrm{pH}$ 10.5. Ionic strength and $\mathrm{pH}$ were immediately adjusted with strong $0.2 \mathrm{M}$ phosphate buffer, $\mathrm{pH} 7$, with $1 \mathrm{M} \mathrm{NaCl}$ leading to fast refolding. Additional purification was done using SEC on Sephacryl S-200 (Amersham Pharmacia Biotech) equilibrated with $0.01 \mathrm{M}$ phosphate buffer, containing $0.12 \mathrm{M} \mathrm{NaCl}$ at $\mathrm{pH}$ 6.1. Purity was checked by SDS-PAGE electrophoresis. 
<smiles>CC(=O)N[C@@H](CS)C(=O)O</smiles>

(a)<smiles>O=C1O[C@H]([C@H](O)CO)C(O)=C1O</smiles>

(b)<smiles>Oc1ccc(/C=C/c2cc(O)cc(O)c2)cc1</smiles>

(c)<smiles>O=c1c(O)c(-c2ccc(O)c(O)c2)oc2cc(O)cc(O)c12</smiles>

(d)<smiles>COc1cc(/C=C/C(=O)CC(=O)/C=C/c2ccc(O)c(OC)c2)ccc1O</smiles>

(e)

FIGURE 1: Structures of (a) NAC, (b) vitamin C, (c) resveratrol, (d) quercetin, and (e) curcumin. Computed chemical and physical properties are given in Supplementary Table S2.

2.3. ThT Fluorescence. ThT dye was used to determine the presence of amyloid fibrils. Fluorescence was measured using a PerkinElmer model LS-50B luminescence spectrometer. Excitation was set to $440 \mathrm{~nm}$, and spectra were recorded from $455 \mathrm{~nm}$ to $600 \mathrm{~nm}$. ThT dye was dissolved in phosphate buffer $(25 \mathrm{mM}, 0.1 \mathrm{M} \mathrm{NaCl}$ at $\mathrm{pH} 7.5)$ at $15 \mu \mathrm{M}\left(A_{416}=0.66\right)$. Fibrils were grown under mild conditions at $\mathrm{pH} \sim 5$ $(0.015 \mathrm{M}$ acetate buffer, $0.15 \mathrm{M} \mathrm{NaCl}$ at $\mathrm{pH} 4.8)$ at room temperature; protein concentrations were $34 \mu \mathrm{M}$. In order to accelerate fibril formation, fibrillation mixtures contained $10 \% \mathrm{v} / \mathrm{v}$ TFE. Fifty microliters of the protein solution in which fibrils were growing was added to $570 \mu \mathrm{L}$ of the ThT buffer just before measurement. A fresh ThT probe was prepared daily. ThT fluorescence was measured using a $0.5 \mathrm{~cm}$ cuvette at $25^{\circ} \mathrm{C}$. Excitation and emission slits were set at $5 \mathrm{~nm}$ and $7 \mathrm{~nm}$, respectively. Data were collected every $0.5 \mathrm{~nm}$. Fluorescence intensities at $482 \mathrm{~nm}$ were plotted against time. Each measurement was performed at least twice in duplicates, and the mean value is presented (average of duplicate measurements \pm standard deviations). The blind probe was followed for each antioxidant and subtracted to get final values.

2.4. Transmission Electron Microscopy. Protein samples (15 $\mu \mathrm{L}$ of $34 \mu \mathrm{M}$ protein solution) were applied on a Formvar- and carbon-coated grid. After $3 \mathrm{~min}$, the sample was soaked away and stained with $1 \%(\mathrm{w} / \mathrm{v})$ uranyl acetate. Samples were observed with a Philips CM100 (FEI, Netherlands) transmission electron microscope operating at $80 \mathrm{kV}$. Images were recorded using a Bioscan or ORIUS SC 200 CCD camera (Gatan Inc., Washington, DC, USA), using the DigitalMicrograph software (Gatan Inc., Washington, DC, USA). Two parallel grids were prepared for each sample, at least 10 grid squares were inspected thoroughly, and many micrographs were taken of each grid.

2.5. Molecular Docking. The molecular docking study was performed using the SwissDock server http://www.swissdock.ch/. SwissDock is based on the docking software EADock DSS, whose algorithm consists of many steps [53]. The target molecules were provided as PDB files (stB wt PDB id: $4 \mathrm{~N} 6 \mathrm{~V}$ ). Chain A of the protein was selected, water molecules and ions were removed, and all hydrogen atoms were added. A uniform procedure led to numerous predictions for each chosen ligand. Binding modes are scored using FullFitness and clustered. Clusters are then ranked using FullFitness of their elements. In consecutive cycles, the structure of the lowest "FullFitness" and estimated $\Delta G$ value was selected and the neighboring docked ligand structures were collected as representative. In other words, only the minimum energy conformation states of the ligand-bound protein complex out of many generated binding modes were considered. Binding modes were visualized in JSmol, and PDB was used for the identification of residues involved in binding.

2.6. ThT Fluorescence Bias Measurement. Fluorescence measurements were done using a TECAN Safire plate reader (Thermo Fisher Scientific) in 96 wells at $25^{\circ} \mathrm{C}$. Solutions of stB wt preformed fibrils were incubated at room temperature in the absence and presence of different final concentrations of antioxidants. An 11.4-fold volume excess of ThT was added to each well prior to fluorescence reading. For each assay, the fluorescence of antioxidant without stB wt with ThT dye was also monitored. The excitation wavelength was set at $440 \mathrm{~nm}$, and the emission wavelength was set from 455 to $600 \mathrm{~nm}$. The emission wavelength step size was $1 \mathrm{~nm}$, and excitation and emission bandwidths were set at $7.5 \mathrm{~nm}$. The fluorescence intensity at $482 \mathrm{~nm}$ was read. Each sample was followed in triplicate, and the mean value is presented.

2.7. Circular Dichroism. Far-UV circular dichroism (CD) spectra were measured at room temperature by using a Circular Dichroism Spectrometer MOS-500 (Bio-Logic Science Instruments). The fibrillation mixture was prepared as described in Section 2.3. Protein concentration was $34 \mu \mathrm{M} \quad\left(A_{280}=0.15\right)$. The temperature was maintained at $25^{\circ} \mathrm{C}$ throughout. A $1 \mathrm{~mm}$ quartz cuvette was used for all CD spectra. Data were recorded from 250 to $200 \mathrm{~nm}$ with a $1 \mathrm{~nm}$ sampling interval. The final spectra were the average of three repeated experiments, and the background 
(the $\mathrm{CD}$ spectrum of the sample without stB wt and antioxidants) was subtracted.

2.8. SDS-PAGE Electrophoresis and Cross-Linking. A fibrillation mixture of stB wt was prepared as described in Section 2.3. Samples aged 24 hours were applied to SDS-PAGE gel using the standard procedure. To make sure that different higher molecular species will remain stable in the presence of SDS and high temperature, we performed cross-linking with $\mathrm{BS}^{3}$ as a cross-linker. Instructions from the manufacturer were followed, and 50-fold molar excess of the crosslinker has been used. $\mathrm{stB}$ wt fibrillation mixture in the absence and presence of the cross-linker was used as control.

\subsection{Steady-State Fluorescence Quenching Measurements.} Steady-state fluorescence quenching measurements of stB wt in the presence of different concentrations of quenchers, that is, antioxidants, were done using the TECAN Safire plate reader (Thermo Fisher Scientific) in 96 wells at $25^{\circ} \mathrm{C}$. The protein concentration was $34 \mu \mathrm{M}$, and antioxidant concentrations were varied. Intrinsic tyrosine fluorescence was measured by exciting protein at $277 \mathrm{~nm}$, and emission spectra were recorded in the range of 290 to $360 \mathrm{~nm}$. The excitation and emission slit widths were set at $7.5 \mathrm{~nm}$, whereas emission wavelength step size was set to $1 \mathrm{~nm}$. Each measurement was done in triplicate. The data were analyzed according to the Stern-Volmer equation:

$$
\frac{F_{\mathrm{o}}}{F}=K_{\mathrm{sv}}[Q]+1,
$$

where $F_{\mathrm{o}}$ and $F$ are the fluorescence intensities in the absence and presence of quenchers, that is, antioxidants, and $K_{\mathrm{sv}}$ is the Stern-Volmer quenching constant. Binding constants and binding sites were obtained from (2), which is basically a modified Stern-Volmer equation:

$$
\log \left(F_{\mathrm{o}}-\frac{F}{F}\right)=\log K_{\mathrm{a}}+n \log [Q],
$$

where $K_{\mathrm{a}}$ is the association constant and $n$ is the number of binding sites [54].

\section{Results}

The main goal of our study was to assess the effects of different antioxidants on the fibrillation profile of our model protein-human stefin B (stB). Therefore, we have chosen three polyphenols and two compounds with a more simple structure (Figure 1). Firstly, their effects on the amyloid fibrillation profile of stB were followed using ThT fluorescence measurements. It is a usual tool as ThT fluorescence increases in the presence of amyloid fibrils and hence is usually used to characterize inhibitors of amyloid fibrillation reaction. However, precaution is obligatory because ThT fluorescence can be quenched by polyphenol compounds [55-57]. As a complementary tool, TEM images were recorded in the plateau phase of the reaction. As described in the Methods section, for each sample, 2 grids were prepared and many images of each were observed to obtain an estimate of the yield of amyloid fibrils. TEM data

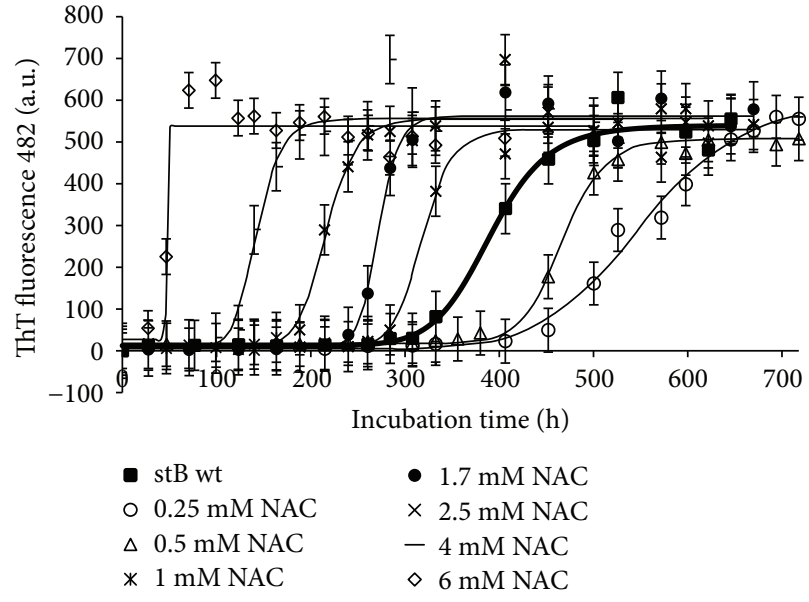

Figure 2: Aggregation kinetics of stefin B monitored by ThT binding/fluorescence in the absence and presence of different concentrations of NAC. ThT fluorescence emission at $482 \mathrm{~nm}$ was monitored upon excitation at $440 \mathrm{~nm}$. Protein concentration was $34 \mu \mathrm{M}$, and concentrations of NAC were varied. Each sample was incubated at room temperature in $0.015 \mathrm{M}$ acetate buffer, $0.15 \mathrm{M}$ $\mathrm{NaCl}$ at $\mathrm{pH} 4.8$, prior to mixing with the ThT probe as described in Section 2.

mostly support ThT fluorescence results; however, when quenching was indicated, we measured the ThT fluorescence bias (Supplementary Figure S1). Furthermore, molecular docking was performed in order to obtain predictions of the binding mode for each of the antioxidants. Additional data regarding binding constants were provided using steadystate fluorescence quenching measurements and SternVolmer constants. Alterations of the secondary structure were checked using circular dichroism. The oligomeric state was determined using cross-linking prior to SDS-PAGE electrophoresis. Results are described in this section and analyzed in the Discussion section. One part of the results is presented and elaborated in Supplementary materials.

Results of the concentration dependence of NAC and vitamin $\mathrm{C}$ on fibril growth as judged by ThT fluorescence are gathered in Figures 2 and 3. In Figure 2, it can be seen that NAC from 1 to $6 \mathrm{mM}$ concentrations (average molar ratio 100:1 NAC to protein) promotes protein aggregation, that is, it reduces the lag phase. The final ThT fluorescence intensity does not change substantially (Figure 2); neither does TEM show influence on the final yield or morphology of the mature amyloid fibrils (Figure 4(b) shows $4.0 \mathrm{mM}$ NAC). Lower concentrations, that is, $0.25 \mathrm{mM}$ and $0.5 \mathrm{mM}$ NAC, inhibit fibril growth, that is, prolong the lag phase.

In Figure 3, it can be seen that vitamin $\mathrm{C}$ at $2.5 \mathrm{mM}$ and $4 \mathrm{mM}$ concentrations also accelerates the reaction of amyloid fibril formation, that is, shortens the lag phase and lowers the final amount of mature fibrils as judged by ThT fluorescence intensity (Figure 3). This lowering of fluorescence may be partially due to a quenching effect as TEM does not show a lower quantity of mature fibrils at $4 \mathrm{mM}$ or $2.5 \mathrm{mM}$ vitamin C concentrations (Figures 4(c) and 4(d)). At lower concentration, vitamin $\mathrm{C}$ acts similarly to NAC; the lag phase is prolonged. Noteworthily, vitamin $\mathrm{C}$ at the 


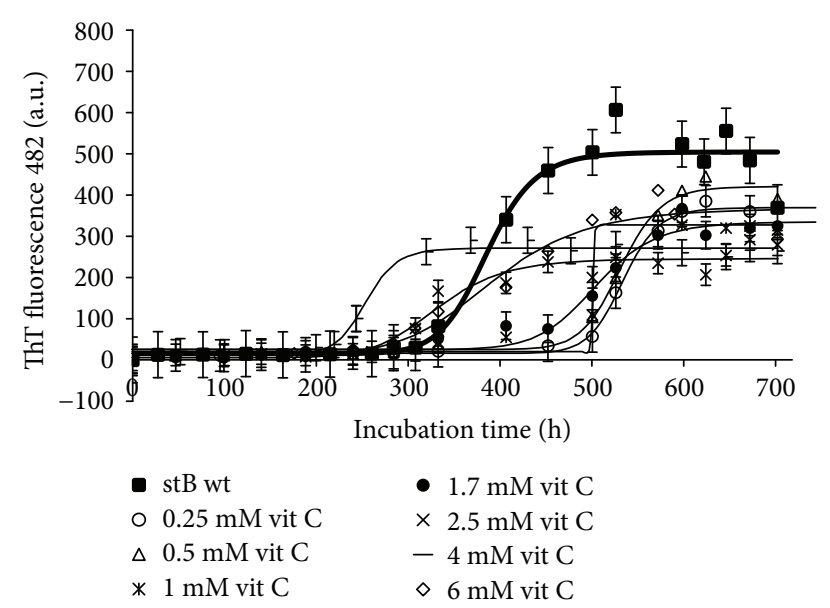

FIgURE 3: Aggregation kinetics of stefin B monitored by ThT binding/fluorescence in the absence and presence of different concentrations of vitamin $\mathrm{C}$ (vit $\mathrm{C}$ ). ThT fluorescence emission at $482 \mathrm{~nm}$ was monitored upon excitation at $440 \mathrm{~nm}$. Protein concentration was $34 \mu \mathrm{M}$, and a concentration of vit $\mathrm{C}$ was varied. Each sample was incubated at room temperature in $0.015 \mathrm{M}$ acetate buffer, $0.15 \mathrm{M} \mathrm{NaCl}$ at $\mathrm{pH} 4.8$, prior to mixing with the ThT probe as described in Section 2.

$0.25 \mathrm{mM}$ concentration inhibits fibril growth, that is, prolongs the lag phase (Figure 3 ) and lowers the mass of fibrils on account of the aggregates as shown by TEM (Figure 4(e)).

We have also measured the effect of vitamin E dissolved in ethanol. No significant effect of this vitamin either on the lag phase or on ThT intensity was observed (data not shown). Fibrils were not inhibited in this case (TEM data not shown).

Results of different concentrations of the three polyphenols resveratrol, quercetin, and curcumin on ThT fluorescence are shown in Figures 5-7. Resveratrol (Figure 5) shows no significant effect on the lag phase, whereas ThT fluorescence intensity slightly decreases in a concentrationdependent manner. However, TEM data (Figures 8(d) and 9(b), F-H) show more aggregates remaining, pointing to a quenching effect (Supplementary Figure S1). Quercetin (Figure 6) prolongs the lag phase; however, this effect is less expressed than for curcumin (Figure 7). Interestingly, when compared to other antioxidants, quercetin shows a different behavior. According to TEM results, more aggregates remain and, in some regions, fibrils look more amorphous (Figure 8(e)). Curcumin affects the lag phase the most (Figure 7), and it also reduces the final ThT fluorescence the most. However, this observation may be due to a strong quenching effect (Supplementary Figure S1). In order to assess the differences in the final quantity of fibrils at certain curcumin concentrations, we have to rely on TEM (Figures 8(f) and 9(b), A-C). This method is not meant to test the amount of the fibrils quantitatively; many grids have to be observed until statistically valid amounts can be estimated. Still, it enables us to estimate the effects of different antioxidants on the final yield and morphology of the aggregates, and the relation between the forms.

We have also measured how the concentration dependence of the three polyphenolic antioxidants, that is, Res,
Quer, and Cur, reflects on ThT fluorescence measured at the lag phase of stB fibrillation (Figure 9(a)) as compared to TEM (Figure 9(b)). It can be seen that ThT fluorescence intensity is inversely proportional to the concentration of Res, that is, fluorescence decreases as the concentration of the antioxidant increases (Figure 9(a)). Quer and Cur act similarly-the lowest concentration of both antioxidants did not affect amyloid fibrillation at all or the effect was minor in the case of $1 \mu \mathrm{M}$ Cur, whereas higher concentrations caused a reduction in fluorescence intensity. However, this effect was more pronounced in the case of Cur (Figure 9(a)). TEM images partially reflect these results (Figure 9(b)). According to TEM results, the final quantity of fibrils in the presence of higher concentrations of Cur (Figure 9(b), C) is lower than in the presence of lower concentrations (Figure 9(b), A). Effects of Quer are specific (Figure 9(b), D and E), and many aggregates are visible in the case of both concentrations. When compared to control, fibrils are shorter and thicker and appear sticky when Cur or Quer is present. TEM data for Res partly support ThT fluorescence results (Figure 9(b), F-H); the inhibitory effect of $100 \mu \mathrm{M}$ Res is more obvious than that of $50 \mu \mathrm{M}$ Res. In the case of $200 \mu \mathrm{M}$ Res, more fibrils are visible.

CD spectra in the far-UV region have not shown any significant change in the secondary structure of stB wt samples aged 24 hours at given concentrations of antioxidants (Supplementary Figure S2). In order to determine the oligomeric state, the fibrillation mixture was subjected to FPLC analysis on Superdex 75 and cross-linking prior to application on the SDS-PAGE gel. The FPLC elution profile could not be used as a reliable result because the protein severely aggregated in the presence of different antioxidants (data not shown). However, SDS-PAGE electrophoresis after cross-linking with $\mathrm{BS}^{3}$ has shown that antioxidants shift the equilibrium to higher forms, such as tetramers and higher oligomers (Supplementary Figure S3. Tetramers and higher oligomers are marked with an arrow). According to the gel, when protein is exposed to antioxidants, there are more dimers as well, than in the case of the control (Supplementary Figure S3).

A molecular docking study has offered predictions of binding modes for each antioxidant (Figure 10). Thanks to SwissDock, it was possible to obtain docking prediction in JSmol and binding parameters based on the inserted $\mathrm{PDB}$ code for stB and the specific structure of the antioxidant. Databank was used to determine amino acid residues that participate in specific protein-ligand interactions (Supplementary Table S1). Interestingly, the program has offered many prediction variants for each antioxidant with the exception of curcumin; this antioxidant has each time been positioned within the same pocket (Figure 10(e), Supplementary Table S1). This observation is supported by results of intrinsic Tyr fluorescence measurements (Supplementary Figures S4E and S5B, D). Supplementary Figure S4E shows a significant decrease in Tyr fluorescence intensity in a concentration-dependent manner, and SternVolmer plots and binding constants show that curcumin binds more tightly than do other antioxidants studied here (Supplementary Figure S5B, D). 


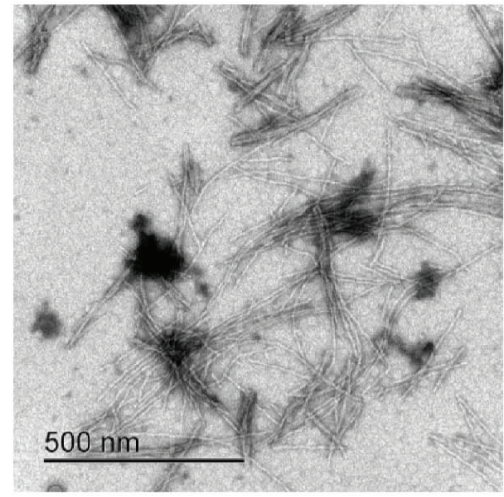

(a)

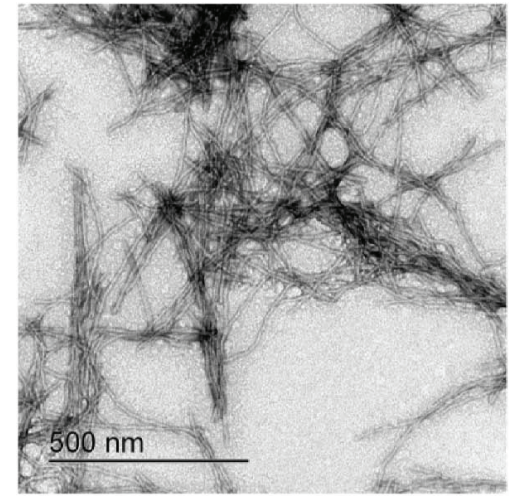

(b)

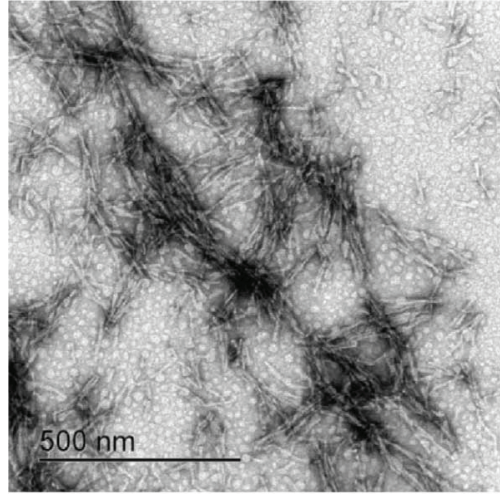

(c)

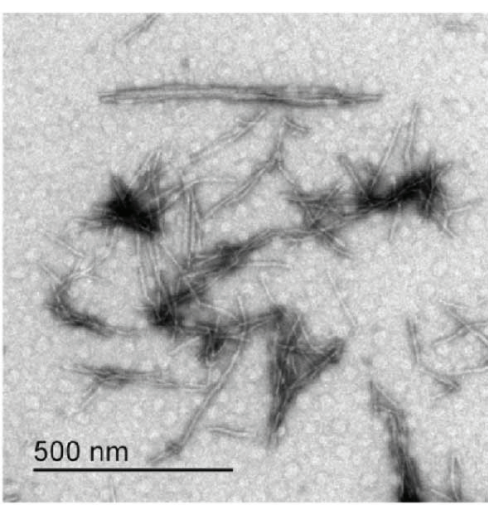

(d)

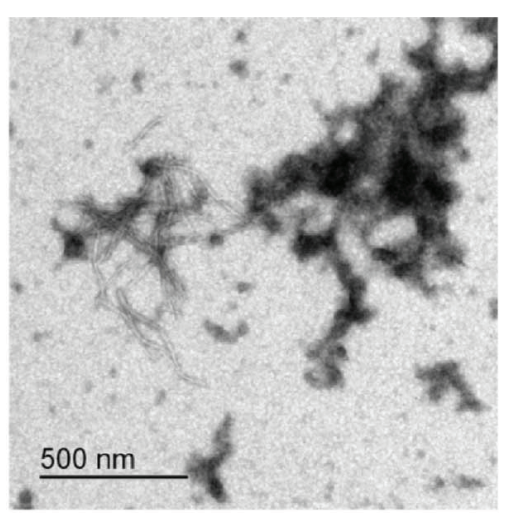

(e)

Figure 4: TEM data at the plateau of the fibrillation reaction by stefin B. Control: (a) stB in water. Samples: (b) stB with NAC at 4.0 mM and (c) stB with vitamin $\mathrm{C}$ at $4.0 \mathrm{mM}$, (d) $2.5 \mathrm{mM}$, and (e) $0.25 \mathrm{mM}$.

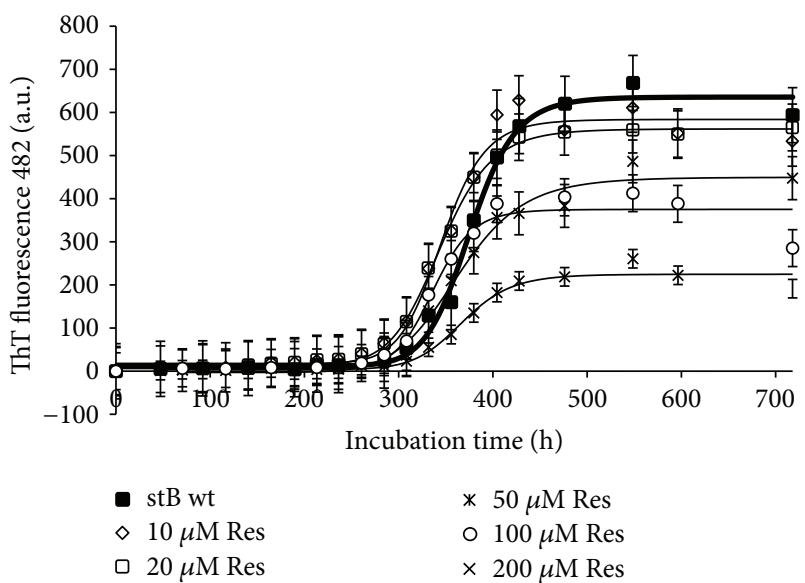

FIGURE 5: Effect of resveratrol on amyloid fibril formation by stefin B. Aggregation kinetics monitored by ThT binding in the absence and presence of different concentrations of Res. The inhibitory effect on amyloid formation of stB wt was monitored by following the ThT fluorescence emission at $482 \mathrm{~nm}$ upon excitation at $440 \mathrm{~nm}$. Concomitantly, the aggregation behavior of stB wt with final $1 \% \mathrm{v} / \mathrm{v}$ DMSO was followed each day as a control because Res was dissolved in DMSO to a final $1 \% \mathrm{v} / \mathrm{v}$. Protein concentration was $34 \mu \mathrm{M}$, and concentrations of Res were varied.

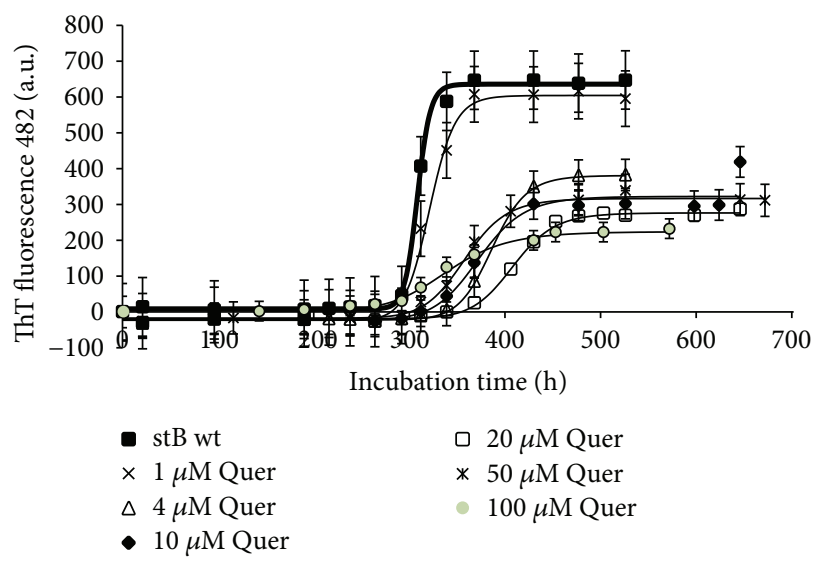

FIgURE 6: Effect of quercetin on amyloid fibril formation by stefin B. Measurement was done by following ThT fluorescence-as described in Figure 5.

\section{Discussion}

Protein self-assembly into amyloid fibrillary state is characteristic of numerous debilitating diseases [2]. It is known that natural organic dyes, for example, Congo Red, bind tightly to proteins and hence block their self-assembly. The ability of this and other molecules to prevent amyloid accumulation has generated an immense interest in elucidating their key 


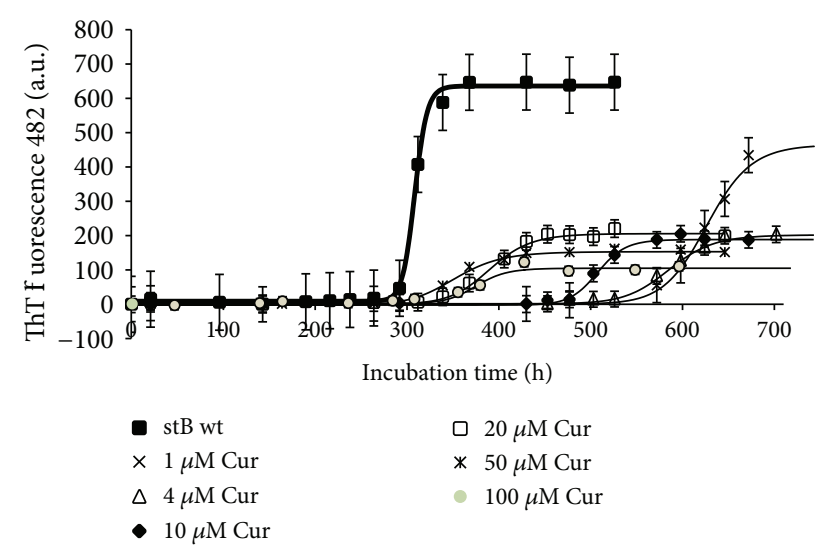

FIGURE 7: Effect of curcumin on amyloid fibril formation by stefin B. Measurement was done by following ThT fluorescence-as described in Figure 5.

structural properties which contribute to inhibitory potency $[34,58,59]$. It is clear that a better understanding of the structure-activity relationships would facilitate the creation of new protein aggregation inhibitors. In turn, these insights might be crucial for deciphering the key elements of the amyloid fibrillation puzzle. Thus, the main goal of this study was to understand at which point the chosen compounds influence protein aggregation reaction and which structural features of the compounds may explain their antiamyloid activity toward our model protein-human stefin B.

The idea that some polyphenolic compounds may interfere with protein aggregation is not new. So far, it is well known that ligands which interfere with amyloid fibrils are flat, planar molecules with substituted aromatic end groups [60]. The first such mention dates back to 2004 when the authors Ono et al. examined the effects of curcumin and rosmarinic acid (RA) on the formation, extension, and destabilization of $\mathrm{fA} \beta(1-40)$ and $\mathrm{fA} \beta(1-42)$ [61]. Cur and RA dosedependently inhibited $\mathrm{fA} \beta$ formation from $\mathrm{A} \beta(1-40)$ and $\mathrm{A} \beta(1-42)$, as well as their extension. In addition, they dosedependently destabilized preformed $\mathrm{fA} \beta \mathrm{s}$ [61]. Moreover, in 2006 Porat et al. suggested an additional mechanism of Cur action [28]. By then, the inhibition mechanism of polyphenol antioxidants had been mostly considered as a result of their antioxidative properties. Taking into consideration that polyphenols are capable of inhibiting amyloid fibril formation in vitro and in view of their structural similarities, these authors proposed an additional mechanism of action. They suggested that both structural constraints and specific aromatic interactions are important for the inhibition of amyloid fibril formation as they provide proper positioning of the polyphenol inhibitors in the amyloidogenic core.

Our study aimed at showing the effect of various antioxidant substances on the kinetics, yield, and morphology of amyloid fibrils formed by human stefin B in vitro. We believe that it mimics other similar systems. To follow the amount of amyloid fibrils, ThT fluorescence measurement was used. It is a usual tool as ThT fluorescence increases in the presence of amyloid fibrils and hence can be used to characterize inhibitors of amyloid fibrillation reaction. However, this assay can be biased by the presence of exogenous compounds, in our case polyphenols, NAC, and vitamin C. There is a study on the interference of the three polyphenols to the intensity of ThT fluorescence [55]. In that study, authors have shown that when it comes to quantification of amyloid fibril formation in the presence of polyphenols, ThT fluorescence should be interpreted with caution. In other words, such compounds can significantly bias ThT fluorescence due to a quenching effect [55]. Therefore, we have checked the quenching properties of each of the chosen antioxidant. Supplementary Figure S1 shows that each compound acts as a quencher of ThT fluorescence. However, results obtained by TEM and the differences in the lag time in ThT fluorescence are still valid to evaluate the inhibitory effects of these compounds on protein aggregation to amyloid fibrils and therefore worth discussing.

ThT fluorescence measurements have not detected any major decrease in the intensity when different concentrations of NAC were added to the stB fibrillation mixture. TEM images similarly did not show any significant difference in the final yield and morphology of stB fibrils (Figure 2 and $4(\mathrm{~b}))$. On the other hand, the lag phase varied in a concentration-dependent manner, that is, higher concentrations have shortened the lag phase, whereas lower concentrations have prolonged it (Figure 2). Noteworthily, a similar behavioral pattern can be observed in the case of vit $\mathrm{C}$ (Figure 3), which can probably be explained as their significant influence on the microenvironment of the amyloidogenic core. This observation is not due to $\mathrm{pH}$ change because, in our hands, antioxidants did not alter $\mathrm{pH}$. Moreover, electrophoretic techniques can help in determining oligomer sizes in the fibrillation mixture [62]. In our study, SDS-PAGE electrophoresis upon cross-linking has shown that antioxidants NAC and vit $\mathrm{C}$ shift the equilibrium to higher forms such as tetramers and higher oligomers (Figure S3; tetramers with a molecular mass of $\sim 44 \mathrm{kDa}$ and higher oligomers are marked with arrows). Similar observations have already been described by other authors [63, 64]. According to the gel, there are more dimers (molecular mass $\sim 22 \mathrm{kDa}$, marked with an arrow) than in the case of the control (Figure S3). Higher oligomers appear only when protein is exposed to very high concentrations of antioxidants, in our case $2.5 \mathrm{mM}$ and $6 \mathrm{mM}$ vit $\mathrm{C}$ (Figure S3, lanes 6 and 7) and $2.5 \mathrm{mM}$ and $6 \mathrm{mM}$ NAC (Figure S3, lanes 9 and 10). Of note, the highest concentrations of both NAC and vit $\mathrm{C}$ decreased the lag phase length (Figures 2 and 3).

If we compare our data to the effect of vitamin $\mathrm{C}$ to amyloid fibril formation of $\beta$-lactoglobulin [27], a similar inhibitory effect is observed. Vitamin $\mathrm{C}$ inhibits the fibril formation of stefin B in the range of concentrations from $0.25 \mathrm{mM}$ to $0.5 \mathrm{mM}$, both by prolonging the lag phase (Figure 3) and by diminishing the final amount of the fibrils, as judged by TEM (Figure 4(e)). Note that ThT may be prone to quenching effects; therefore, one should dissect whether lower fluorescence indeed means a lower amount of the fibrils [55]. Vitamin $\mathrm{C}$ at higher concentrations than $0.5 \mathrm{mM}$ (Figure 3) decreases the lag phase and promotes aggregation, similarly to NAC. Final ThT fluorescence appears much lower whereas TEM shows a similar amount 


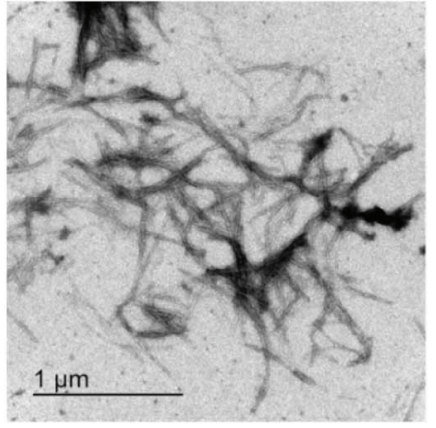

(a)

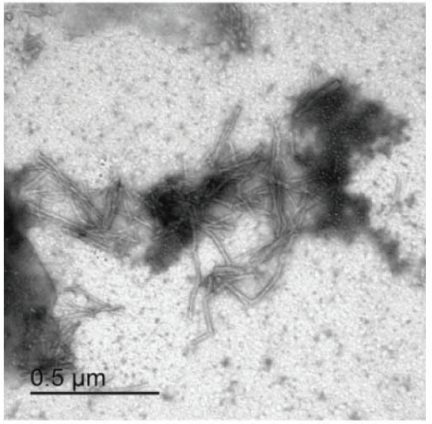

(d)

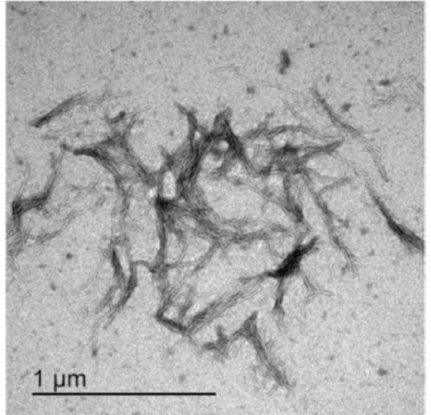

(b)

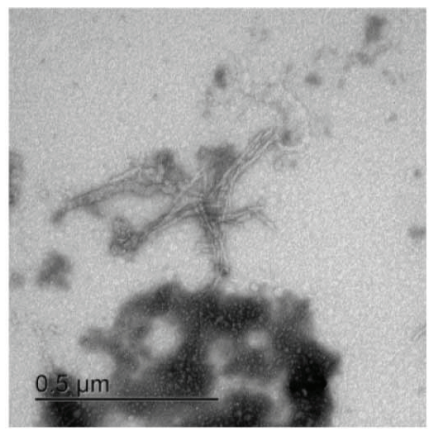

(e)

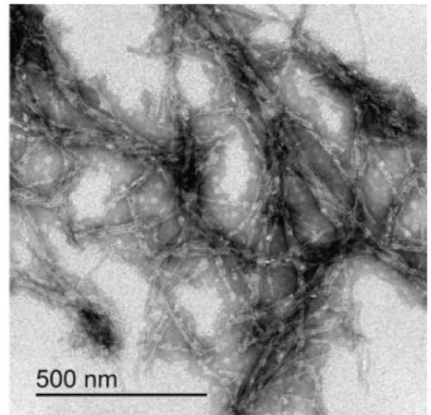

(c)

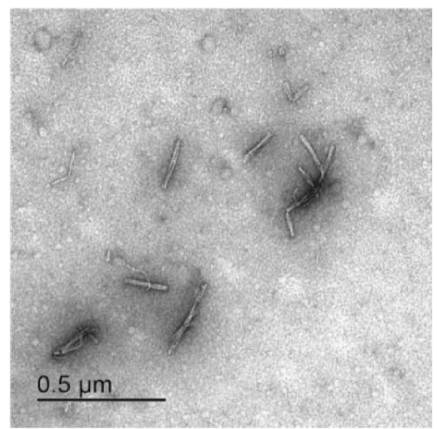

(f)

FIGURE 8: TEM data collected at the plateau of the reactions of amyloid fibril formation by stefin B in the presence and absence of polyphenols. Controls (a), (b), and (c) show stB in (a) water, (b) in $1 \%$ DMSO, and (c) in $1 \%$ ethanol in comparison to $50 \mu \mathrm{M}$ concentrations of (d) resveratrol, (e) quercetin, and (f) curcumin.

of the fibrils (Figures 4(c) and 4(d)). Here, the discrepancy can best be explained by a severe quenching effect on ThT fluorescence. Lee et al. explained the inhibitory effect of vitamin $C$ through its interference with exposed hydrogen atoms of the $\mathrm{N}-\mathrm{H}$ groups in the $\beta$-sheet backbone [27]. To be specific, metabolites of vitamin $C$, which are generated in the aqueous solution, such as ascorbate anions and dehydroascorbic acid, can shield electrostatic interactions between $\beta$ sheets due to their specific interactions and cause disruption of $\beta$-sheet stacking. This mechanism is different from antioxidation, which is usually considered as a major mechanism of vitamin $\mathrm{C}$ action. It was even reported that it can decrease amyloid plaque burden in the cortex and hippocampus when tested on cross-bred mice [65]. In our study, it was confirmed once more that vit $\mathrm{C}$ has potential as an antiamyloid substance. However, at higher concentrations it may be less beneficial as it increases the most toxic higher oligomers.

The three polyphenols each behave differently. Curcumin at all concentrations inhibited the amyloid fibril formation (Figure 7). Lower concentrations have a greater effect on the prolongation of the lag phase; however, the final mass of the fibrils appears higher. At the concentration of $50 \mu \mathrm{M}$, curcumin both prolongs the lag phase and reduces the amount of mature fibrils. The quantity and morphology of the fibrils at $50 \mu \mathrm{M}$ Cur were checked by TEM and are presented in Figure 8(f). With curcumin, one cannot neglect a quenching effect; therefore, TEM results are more relevant than that using ThT fluorescence. TEM data in Figure 8(f) confirm that curcumin at $50 \mu \mathrm{M}$ inhibits fibril growth.
Noteworthily, the effect follows a concentration-dependent pattern: at lower concentrations, such as $1 \mu \mathrm{M}$ Cur, the fibrils grow longer, whereas at $50 \mu \mathrm{M}$ Cur the fibrils are shorter and fewer (Figure 9(b), A-C). Resveratrol does not reduce the lag phase (Figure 5). It apparently reduces the final yield of the fibrils (Figure 5), which however was not confirmed by TEM (Figure 8(d)). Quercetin slightly prolongs the lag phase (Figure 6). However, more aggregates are produced than the fibrils as can be seen by TEM (Figures $8(\mathrm{e})$ and $9(b), D$ and $E$ ).

Docking studies can provide us with important information and are a very useful tool for understanding the prevailing binding modes between protein and ligands. In order to investigate the possible mode of interaction and determine the most stable complex between stefin B and chosen antioxidants, docking using SwissDock was performed (Figure 10). Docking investigation has offered about 100 different variants for each ligand, and those with the lowest values for free binding energy were chosen (Supplementary Table S1). Interestingly, different positions with different $\Delta G$ values were suggested for each ligand except for curcumin, which was each time positioned in a similar way and had the lowest overall $\Delta \mathrm{G}$ value, as well (Figure 10). When compared to other ligands included in this study, curcumin has a specific chemical scaffold (Figure 1(e)); it contains two substituted aromatic groups symmetrically bound by a short carbohydrate chain. More discussion about why curcumin might be the strongest binder is given in the Supplementary Materials. 


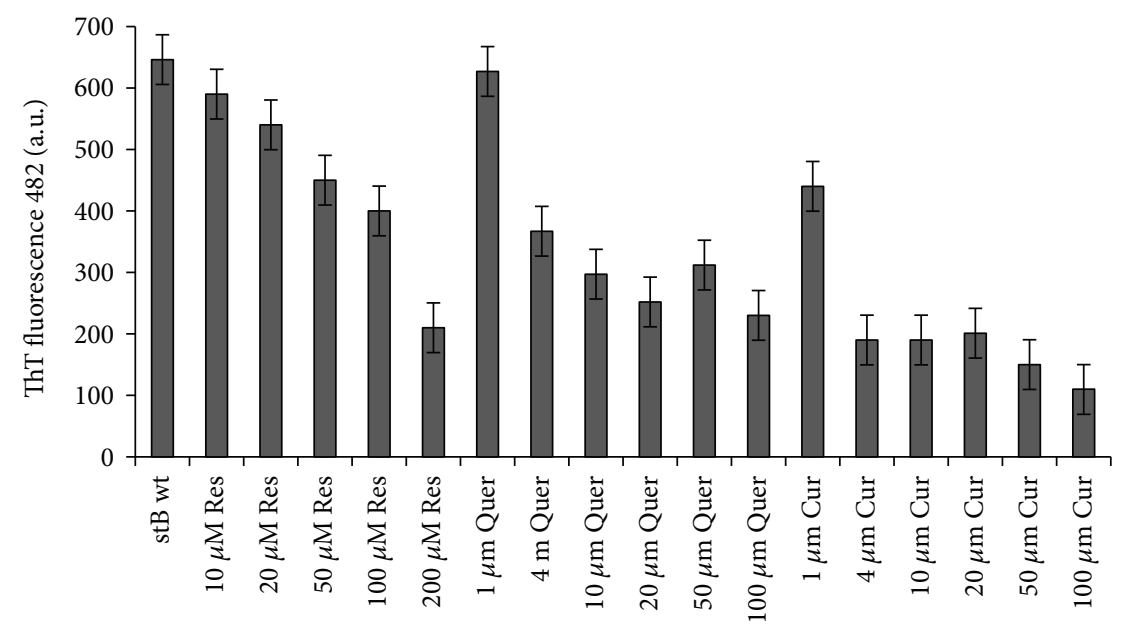

(a)
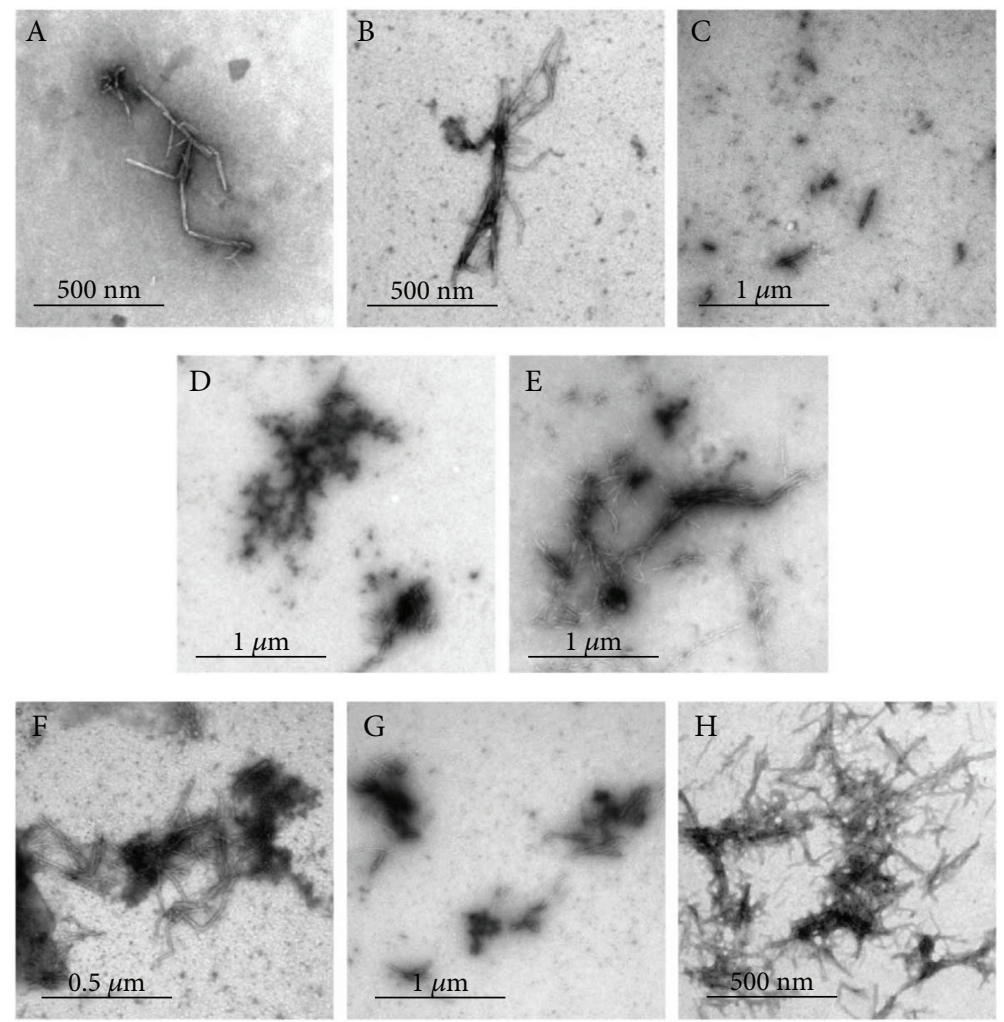

(b)

FIgURE 9: ThT fluorescence intensity versus TEM data. (a) Graph of ThT fluorescence intensity in the plateau phase of amyloid fibrillation versus antioxidant concentration. (b) TEM data. Concentration dependence of fibril morphology and approximate amounts; samples were taken in the plateau phase of the reactions of amyloid fibril formation by stB at different polyphenol concentrations: (A) $1 \mu \mathrm{M}$ Cur, (B) $10 \mu \mathrm{M}$ Cur, (C) $50 \mu \mathrm{M}$ Cur, (D) $1 \mu \mathrm{M}$ Quer, (E) $50 \mu \mathrm{M}$ Quer, (F) $50 \mu \mathrm{M}$ Res, (G) $100 \mu \mathrm{M}$ Res, and (H) $200 \mu \mathrm{M}$ Res.

As a supporting data for docking study, Supplementary Figure $\mathrm{S} 4$ shows that each compound also acts as a quencher of tyrosine fluorescence. The observed reduction of fluorescence intensity indicates that each ligand binds in the vicinity of the tyrosine residue-as they come closer to the Tyr residues in the process of binding, their fluorescence intensity is being reduced. Stefin B is a multityrosine protein as it has three tyrosine residues (Tyr53, Tyr85, and Tyr97). Therefore, at first, it might be a complicated task to clarify which tyrosine could be accessible for the ligands. However, this question can be resolved using docking predictions and the human stefin B structure obtained using X-ray diffraction. More information about amino acid residues which participate in binding is given in Supplementary Table S1.

To conclude, in this study, we have studied the effect of 5 different antioxidant compounds on amyloid fibrillation of stefin B. Our results are mostly in line with other 


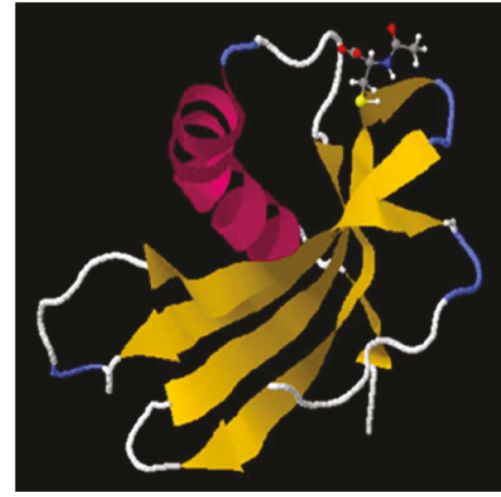

(a)

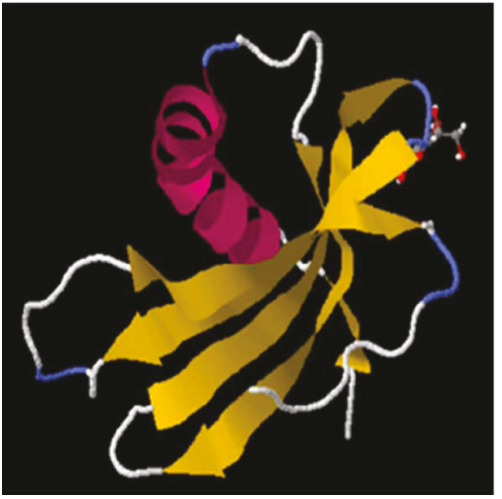

(b)

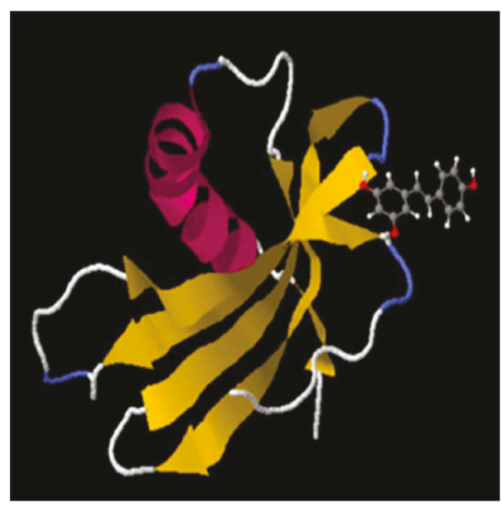

(c)

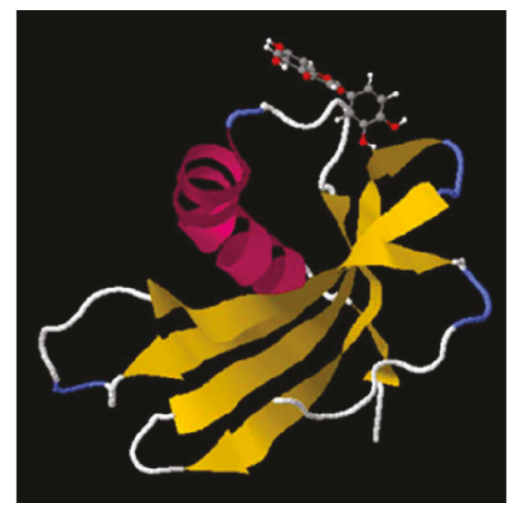

(d)

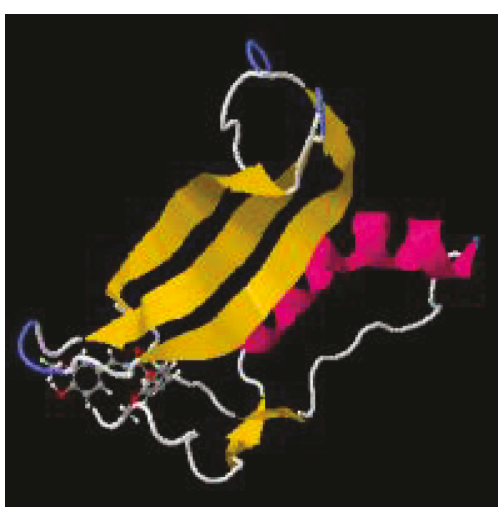

(e)

FIGURE 10: Binding predictions obtained by molecular docking. Molecular docking was performed using SwissDock, and the structures of the most stable stB complexes with (a) NAC, (b) vitamin C, (c) resveratrol, (d) quercetin, and (e) curcumin were selected.

similar studies, showing that antioxidants with flat aromatic structures, as well as vit $\mathrm{C}$ and NAC, can interact with the aggregating protein and inhibit amyloid fibril formation at different stages. The current study highlights and partly confirms the possibility that antioxidant compounds can also fight the formation of toxic oligomers and amyloid fibrils. However, their ROS scavenging effect cannot be neglected. Considering that protein misfolding and aggregation cause many debilitating diseases, future studies are warranted.

\section{Conflicts of Interest}

The authors declare that they have no conflicts of interest.

\section{Authors' Contributions}

Samra Hasanbašić and Alma Jahić contributed equally to this work.

\section{Acknowledgments}

This work was supported by a bilateral $\mathrm{BiH}$-Slovenia grant (BI-BA/16-17-007) led by Selma Berbić (BiH) and Eva Žerovnik (Slovenia) and the program P1-0140 "Proteolysis and its regulation" led by B. Turk (Ljubljana, Slovenia). Samra Hasanbašić was given a fellowship via CMEPIUS for student exchange at the Jožef Stefan International Postgraduate School, Ljubljana, Slovenia.

\section{Supplementary Materials}

Figure S1: effect of Res, Quer, and Cur and vit C on in situ real-time ThT fluorescence. Figure S2: the CD spectra of stB wt assemblies aged 24 hours in the absence and presence of $50 \mu \mathrm{M}$ Res. Figure S3: SDS-PAGE of stB wt assemblies aged 24 hours in the absence and presence of different concentrations of antioxidants; samples apart from those in lane 1 were cross-linked before SDS-PAGE. Table S1: molecular docking parameters of the antioxidant-protein interaction. Table S2: computed chemical and physical properties from https://pubchem.ncbi.nlm.nih.gov/. Figure S4: steadystate fluorescence quenching measurements of stB wt in the presence of different concentrations of quenchers, that is, antioxidants. Figure S5: Stern-Volmer plots and modified Stern-Volmer plots of the fluorescence quenching constant for antioxidant-protein complexes. (Supplementary Materials)

\section{References}

[1] A. Berry, "Protein folding and its links with human disease," Biochemical Society Symposium, vol. 68, pp. 1-26, 2001.

[2] F. U. Hartl, "Protein misfolding diseases," Annual Review of Biochemistry, vol. 86, no. 1, pp. 21-26, 2017. 
[3] T. P. Knowles, M. Vendruscolo, and C. M. Dobson, "The amyloid state and its association with protein misfolding diseases," Nature Reviews Molecular Cell Biology, vol. 15, no. 6, pp. 384396, 2014.

[4] A. B. Ahmed and A. V. Kajava, "Breaking the amyloidogenicity code: methods to predict amyloids from amino acid sequence," FEBS Letters, vol. 587, no. 8, pp. 1089-1095, 2013.

[5] A. C. Tsolis, N. C. Papandreou, V. A. Iconomidou, and S. J. Hamodrakas, "A consensus method for the prediction of 'aggregation-prone' peptides in globular proteins," PLoS One, vol. 8, no. 1, article e54175, 2013.

[6] D. Eisenberg and M. Jucker, "The amyloid state of proteins in human diseases," Cell, vol. 148, no. 6, pp. 1188-1203, 2012.

[7] I. K. Lednev, "Amyloid fibrils: the eighth wonder of the world in protein folding and aggregation," Biophysical Journal, vol. 106, no. 7, pp. 1433-1435, 2014.

[8] P. Sweeney, H. Park, M. Baumann et al., "Protein misfolding in neurodegenerative diseases: implications and strategies," Translational Neurodegeneration, vol. 6, no. 1, p. 6, 2017.

[9] D. B. Richards, L. M. Cookson, A. C. Berges et al., "Therapeutic clearance of amyloid by antibodies to serum amyloid P component," The New England Journal of Medicine, vol. 373, no. 12, pp. 1106-1114, 2015.

[10] N. Pradhan, D. Jana, B. K. Ghorai, and N. R. Jana, "Detection and monitoring of amyloid fibrillation using a fluorescence "switch-on" probe," ACS Applied Materials \& Interfaces, vol. 7, no. 46, pp. 25813-25820, 2015.

[11] K. Tanaka, M. Nishimura, Y. Yamaguchi et al., "A mimotope peptide of $\mathrm{A} \beta 42$ fibril-specific antibodies with $\mathrm{A} \beta 42$ fibrillation inhibitory activity induces anti-A $\beta 42$ conformer antibody response by a displayed form on an M13 phage in mice," Journal of Neuroimmunology, vol. 236, no. 1-2, pp. 27-38, 2011.

[12] I. Morgado, K. Wieligmann, M. Bereza et al., "Molecular basis of $\beta$-amyloid oligomer recognition with a conformational antibody fragment," Proceedings of the National Academy of Sciences of the United States of America, vol. 109, no. 31, pp. 12503-12508, 2012.

[13] M. Landreh, A. Rising, J. Presto, H. Jornvall, and J. Johansson, "Specific chaperones and regulatory domains in control of amyloid formation," The Journal of Biological Chemistry, vol. 290, no. 44, pp. 26430-26436, 2015.

[14] M. Sakono and T. Kidani, "ATP-independent inhibition of amyloid beta fibrillation by the endoplasmic reticulum resident molecular chaperone GRP78," Biochemical and Biophysical Research Communications, vol. 493, no. 1, pp. 500-503, 2017.

[15] Z. Liu, T. Zhou, A. C. Ziegler, P. Dimitrion, and L. Zuo, "Oxidative stress in neurodegenerative diseases: from molecular mechanisms to clinical applications," Oxidative Medicine and Cellular Longevity, vol. 2017, Article ID 2525967, 11 pages, 2017.

[16] K. Brieger, S. Schiavone, F. J. Miller Jr., and K. H. Krause, "Reactive oxygen species: from health to disease," Swiss Medical Weekly, vol. 142, article w13659, 2012.

[17] S. L. Albarracin, B. Stab, Z. Casas et al., "Effects of natural antioxidants in neurodegenerative disease," Nutritional Neuroscience, vol. 15, no. 1, pp. 1-9, 2012.

[18] L. Panzella and A. Napolitano, "Natural phenol polymers: recent advances in food and health applications," Antioxidants, vol. 6, no. 2, p. 30, 2017.
[19] R. Banerjee, "Inhibitory effect of curcumin-Cu(II) and curcumin-Zn(II) complexes on amyloid-beta peptide fibrillation," Bioinorganic Chemistry and Applications, vol. 2014, Article ID 325873, 8 pages, 2014.

[20] G. Anderluh and E. Zerovnik, "Pore formation by human stefin B in its native and oligomeric states and the consequent amyloid induced toxicity," Frontiers in Molecular Neuroscience, vol. 5, p. 85, 2012.

[21] S. Ceru, R. Layfield, T. Zavasnik-Bergant et al., "Intracellular aggregation of human stefin B: confocal and electron microscopy study," Biology of the Cell, vol. 102, no. 6, pp. 319-334, 2010.

[22] M. Polajnar, T. Zavašnik-Bergant, K. Škerget et al., "Human stefin B role in cell's response to misfolded proteins and autophagy," PLoS One, vol. 9, no. 7, article e102500, 2014.

[23] E. Zerovnik, R. A. Staniforth, and D. Turk, “Amyloid fibril formation by human stefins: structure, mechanism \& putative functions," Biochimie, vol. 92, no. 11, pp. 1597-1607, 2010.

[24] E. Zerovnik, "Putative alternative functions of human stefin B (cystatin B): binding to amyloid-beta, membranes, and copper," Journal of Molecular Recognition, vol. 30, article e2562, 2017.

[25] A. Taler-Verčič, S. Hasanbašić, S. Berbić, V. Stoka, D. Turk, and E. Žerovnik, "Proline residues as switches in conformational changes leading to amyloid fibril formation," International Journal of Molecular Sciences, vol. 18, no. 3, p. 549, 2017.

[26] V. Lobo, A. Patil, A. Phatak, and N. Chandra, "Free radicals, antioxidants and functional foods: impact on human health," Pharmacognosy Reviews, vol. 4, no. 8, pp. 118-126, 2010.

[27] W. Lee, I. Kim, S. W. Lee et al., "Quantifying L-ascorbic aciddriven inhibitory effect on amyloid fibrillation," Macromolecular Research, vol. 24, no. 10, pp. 868-873, 2016.

[28] Y. Porat, A. Abramowitz, and E. Gazit, "Inhibition of amyloid fibril formation by polyphenols: structural similarity and aromatic interactions as a common inhibition mechanism," Chemical Biology \& Drug Design, vol. 67, no. 1, pp. 27-37, 2006.

[29] C. B. Pocernich and D. A. Butterfield, "Elevation of glutathione as a therapeutic strategy in Alzheimer disease," Biochimica et Biophysica Acta (BBA) - Molecular Basis of Disease, vol. 1822, no. 5, pp. 625-630, 2012.

[30] L. Xiao, D. Zhao, W. H. Chan, M. M. Choi, and H. W. Li, "Inhibition of beta 1-40 amyloid fibrillation with $\mathrm{N}$-acetyl-Lcysteine capped quantum dots," Biomaterials, vol. 31, no. 1, pp. 91-98, 2010.

[31] J. Kocot, D. Luchowska-Kocot, M. Kielczykowska, I. Musik, and J. Kurzepa, "Does vitamin C influence neurodegenerative diseases and psychiatric disorders?," Nutrients, vol. 9, no. 7, p. 659, 2017.

[32] M. E. Obrenovich, N. G. Nair, A. Beyaz, G. Aliev, and V. P. Reddy, "The role of polyphenolic antioxidants in health, disease, and aging," Rejuvenation Research, vol. 13, no. 6, pp. 631-643, 2010.

[33] B. Catalgol, S. Batirel, Y. Taga, and N. K. Ozer, "Resveratrol: French paradox revisited," Frontiers in Pharmacology, vol. 3, p. 141, 2012.

[34] S. Shariatizi, A. A. Meratan, A. Ghasemi, and M. NematGorgani, "Inhibition of amyloid fibrillation and cytotoxicity of lysozyme fibrillation products by polyphenols," International Journal of Biological Macromolecules, vol. 80, pp. 95106, 2015. 
[35] M. Ramazzotti, F. Melani, L. Marchi et al., "Mechanisms for the inhibition of amyloid aggregation by small ligands," Bioscience Reports, vol. 36, no. 5, article e00385, 2016.

[36] P. Nedumpully-Govindan, A. Kakinen, E. H. Pilkington, T. P. Davis, P. Chun Ke, and F. Ding, "Stabilizing off-pathway oligomers by polyphenol nanoassemblies for IAPP aggregation inhibition," Scientific Reports, vol. 6, no. 1, article 19463, 2016.

[37] Y. Jia, N. Wang, and X. Liu, "Resveratrol and amyloid-beta: mechanistic insights," Nutrients, vol. 9, no. 10, p. 1122, 2017.

[38] J. B. Wang, Y. M. Wang, and C. M. Zeng, "Quercetin inhibits amyloid fibrillation of bovine insulin and destabilizes preformed fibrils," Biochemical and Biophysical Research Communications, vol. 415, no. 4, pp. 675-679, 2011.

[39] R. Malisauskas, A. Botyriute, J. G. Cannon, and V. Smirnovas, "Flavone derivatives as inhibitors of insulin amyloid-like fibril formation," PLoS One, vol. 10, no. 3, article e0121231, 2015.

[40] T. Deckert-Gaudig and V. Deckert, "High resolution spectroscopy reveals fibrillation inhibition pathways of insulin," Scientific Reports, vol. 6, no. 1, p. 39622, 2016.

[41] L. C. López, O. Varea, S. Navarro et al., "Benzbromarone, quercetin, and folic acid inhibit amylin aggregation," International Journal of Molecular Sciences, vol. 17, no. 6no. 12, p. 964 , 2016.

[42] S. Prasad, A. K. Tyagi, and B. B. Aggarwal, "Recent developments in delivery, bioavailability, absorption and metabolism of curcumin: the golden pigment from golden spice," Cancer Research and Treatment, vol. 46, no. 1, pp. 2-18, 2014.

[43] W. M. Berhanu and A. E. Masunov, "Atomistic mechanism of polyphenol amyloid aggregation inhibitors: molecular dynamics study of curcumin, exifone, and myricetin interaction with the segment of tau peptide oligomer," Journal of Biomolecular Structure \& Dynamics, vol. 33, no. 7, pp. 1399-1411, 2015.

[44] M. Venigalla, E. Gyengesi, and G. Munch, "Curcumin and apigenin - novel and promising therapeutics against chronic neuroinflammation in Alzheimer's disease," Neural Regeneration Research, vol. 10, no. 8, pp. 1181-1185, 2015.

[45] P. P. Rao, T. Mohamed, K. Teckwani, and G. Tin, "Curcumin binding to beta amyloid: a computational study," Chemical Biology \& Drug Design, vol. 86, no. 4, pp. 813-820, 2015.

[46] C. F. Lin, K. H. Yu, C. P. Jheng, R. Chung, and C. I. Lee, "Curcumin reduces amyloid fibrillation of prion protein and decreases reactive oxidative stress," Pathogens, vol. 2, no. 4, pp. 506-519, 2013.

[47] A. Rabiee, A. Ebrahim-Habibi, A. Ghasemi, and M. NematGorgani, "How curcumin affords effective protection against amyloid fibrillation in insulin," Food \& Function, vol. 4, no. 10, pp. 1474-1480, 2013.

[48] S. Palmal, A. R. Maity, B. K. Singh, S. Basu, N. R. Jana, and N. R. Jana, "Inhibition of amyloid fibril growth and dissolution of amyloid fibrils by curcumin-gold nanoparticles," Chemistry - A Eropean Journal, vol. 20, no. 20, pp. 6184-6191, 2014.

[49] K. N. Liu, C. M. Lai, Y. T. Lee et al., "Curcumin's preincubation temperature affects its inhibitory potency toward amyloid fibrillation and fibril-induced cytotoxicity of lysozyme," Biochimica et Biophysica Acta (BBA) - General Subjects, vol. 1820, no. 11, pp. 1774-1786, 2012.

[50] S. Wang, X. Peng, L. Cui et al., "Synthesis of water-soluble curcumin derivatives and their inhibition on lysozyme amyloid fibrillation," Spectrochimica Acta Part A: Molecular and Biomolecular Spectroscopy, vol. 190, pp. 89-95, 2018.
[51] M. Mazaheri, A. A. Moosavi-Movahedi, A. A. Saboury, F. Khodagholi, F. Shaerzadeh, and N. Sheibani, "Curcumin protects $\beta$-lactoglobulin fibril formation and fibril-induced neurotoxicity in PC12cells," PLoS One, vol. 10, no. 7, article e0133206, 2015.

[52] A. Taler-Verčič, T. Kirsipuu, M. Friedemann et al., "The role of initial oligomers in amyloid fibril formation by human stefin B," International Journal of Molecular Sciences, vol. 14, no. 12, pp. 18362-18384, 2013.

[53] A. Grosdidier, V. Zoete, and O. Michielin, "EADock: docking of small molecules into protein active sites with a multiobjective evolutionary optimization," Proteins, vol. 67, no. 4, pp. 1010-1025, 2007.

[54] M. Skrt, E. Benedik, C. Podlipnik, and N. P. Ulrih, "Interactions of different polyphenols with bovine serum albumin using fluorescence quenching and molecular docking," Food Chemistry, vol. 135, no. 4, pp. 2418-2424, 2012.

[55] S. A. Hudson, H. Ecroyd, T. W. Kee, and J. A. Carver, "The thioflavin $\mathrm{T}$ fluorescence assay for amyloid fibril detection can be biased by the presence of exogenous compounds," The FEBS Journal, vol. 276, no. 20, pp. 5960-5972, 2009.

[56] J. Baell and M. A. Walters, "Chemistry: chemical con artists foil drug discovery," Nature, vol. 513, no. 7519, pp. 481-483, 2014.

[57] E. Coelho-Cerqueira, A. S. Pinheiro, and C. Follmer, "Pitfalls associated with the use of Thioflavin-T to monitor antifibrillogenic activity," Bioorganic \& Medicinal Chemistry Letters, vol. 24, no. 14, pp. 3194-3198, 2014.

[58] P. Patel, K. Parmar, and M. Das, "Inhibition of insulin amyloid fibrillation by Morin hydrate," International Journal of Biological Macromolecules, vol. 108, pp. 225-239, 2017.

[59] V. Sharma and K. S. Ghosh, "Inhibition of amyloid fibrillation and destabilization of fibrils of human $\gamma \mathrm{D}$-crystallin by direct red 80 and orange G," International Journal of Biological Macromolecules, vol. 105, Part 1, pp. 956-964, 2017.

[60] A. A. Reinke and J. E. Gestwicki, "Structure-activity relationships of amyloid beta-aggregation inhibitors based on curcumin: influence of linker length and flexibility," Chemical Biology \& Drug Design, vol. 70, no. 3, pp. 206-215, 2007.

[61] K. Ono, K. Hasegawa, H. Naiki, and M. Yamada, "Curcumin has potent anti-amyloidogenic effects for Alzheimer's $\beta$-amyloid fibrils in vitro," Journal of Neuroscience Research, vol. 75, no. 6, pp. 742-750, 2004.

[62] N. E. Pryor, M. A. Moss, and C. N. Hestekin, "Unraveling the early events of amyloid- $\beta$ protein $(\mathrm{A} \beta)$ aggregation: techniques for the determination of $\mathrm{A} \beta$ aggregate size," International Journal of Molecular Sciences, vol. 13, no. 12, pp. 3038-3072, 2012.

[63] M. T. Ardah, K. E. Paleologou, G. Lv et al., "Structure activity relationship of phenolic acid inhibitors of $\alpha$-synuclein fibril formation and toxicity," Frontiers in Aging Neuroscience, vol. 6, p. 197, 2014.

[64] X. Meng, L. A. Munishkina, A. L. Fink, and V. N. Uversky, "Effects of various flavonoids on the $\alpha$-synuclein fibrillation process," Parkinson's Disease, vol. 2010, Article ID 650794, 16 pages, 2010.

[65] S. Y. Kook, K. M. Lee, Y. Kim et al., "High-dose of vitamin C supplementation reduces amyloid plaque burden and ameliorates pathological changes in the brain of 5XFAD mice," Cell Death \& Disease, vol. 5, no. 2, article e1083, 2014. 


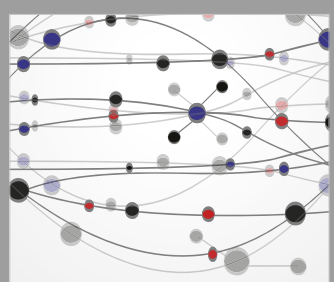

The Scientific World Journal
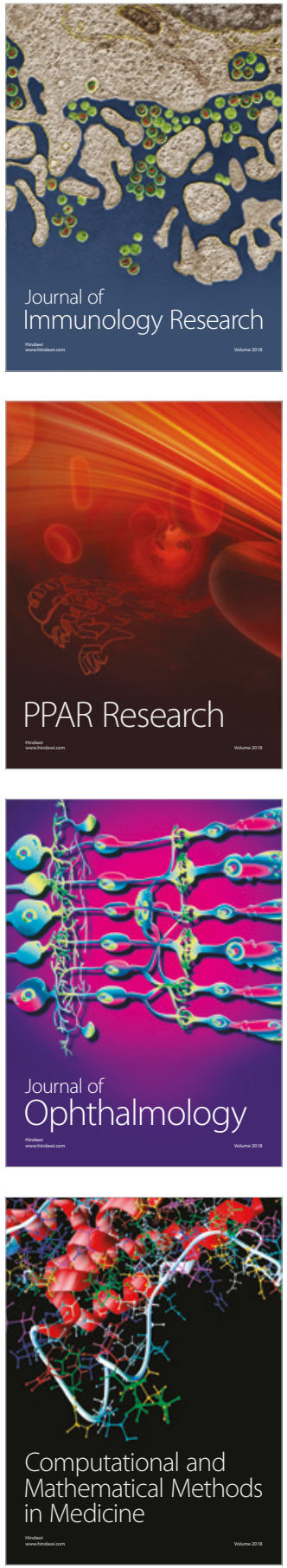

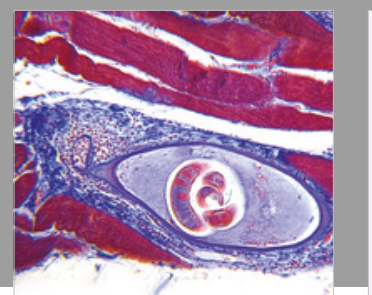

Gastroenterology Research and Practice

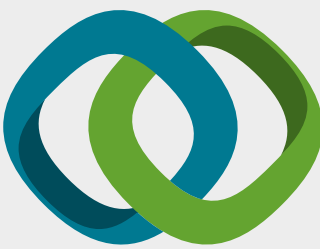

\section{Hindawi}

Submit your manuscripts at

www.hindawi.com
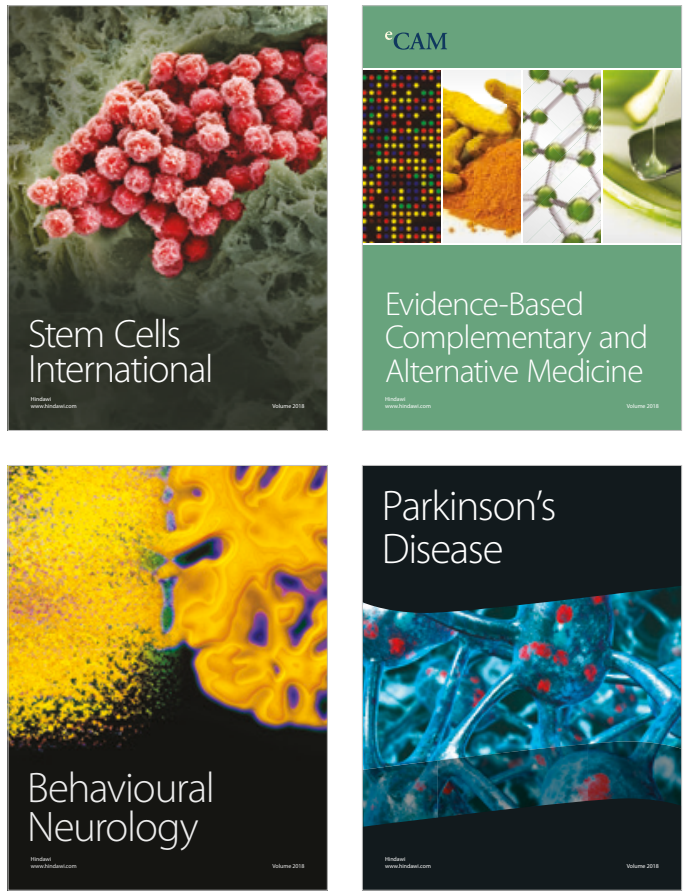

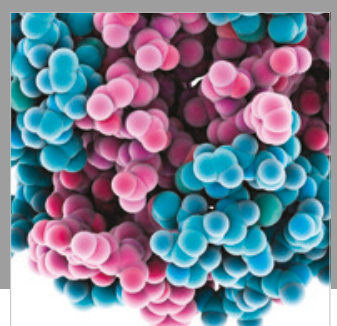

ournal of

Diabetes Research

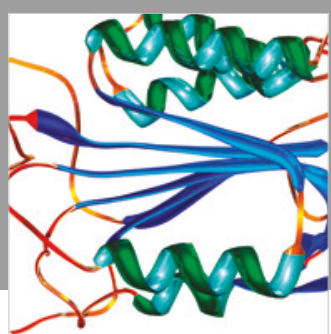

Disease Markers
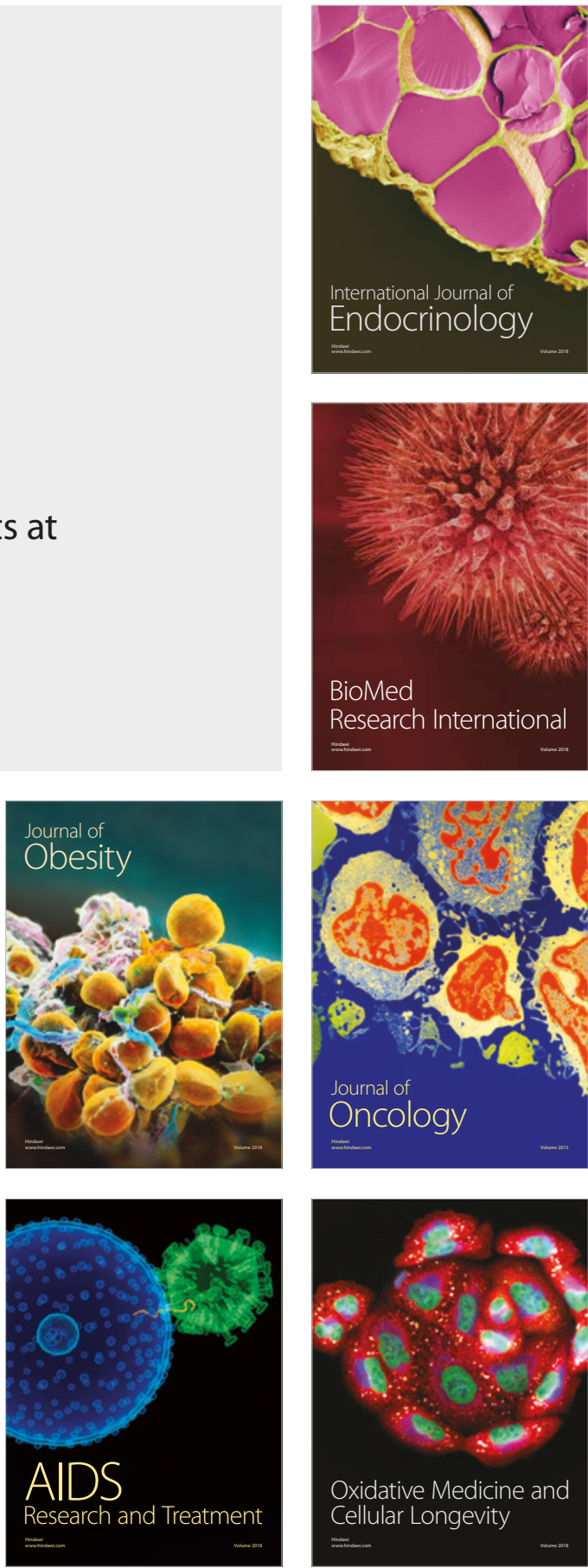